\title{
Coordination of the professional activities in the management system of urban development
}

\author{
Yuri Alekseev ${ }^{1 *}$ \\ ${ }^{1}$ National Research Moscow State University of Civil Engineering, 129337, 26 Yaroslavskoye sh., \\ Moscow, Russia
}

\begin{abstract}
The relevance of the scientific research is the need to create a coordinating system that ensures the unification of the interests of the participants of urban planning activities (scientists, planners, designers, authorities, investors, educational institutions, residents) for the organized performance of professional functions. The purpose of creating such a system is to make the actions of the participants of urban planning activities coherent when making decisions based on a unified approach to the development of diverse planning concepts for the development of the territorial-spatial structure of the settlements that effectively take into account the socio-economic and environmental conditions for the development of society. To develop the coordinating system, the system analysis method was used, including a differentiated and comprehensive account of the patterns of interconnection between the components of the model of the structural organization of the settlements when carrying out urban planning activities in accordance with the urban planning policy.
\end{abstract}

\section{Introduction}

For the modern urban planning, objective prediction of the future processes and phenomena in the urban planning formations of the settlements is required.

Justification of such a forecast is possible on the basis of the laws and principles of the formation of the interrelated and interdependent components of the land, underground, above-ground, underwater buildings and structures (the object I); territories of the settlements and regions in the level of the land surface and the aquatic environment (the object II); the natural land complex (the object III); the elevated territories (the object IV), included in the model of their structural organization in urban planning entities in figure 1 [1].

\footnotetext{
* Corresponding author : alekseev-grado@yandex.ru
} 


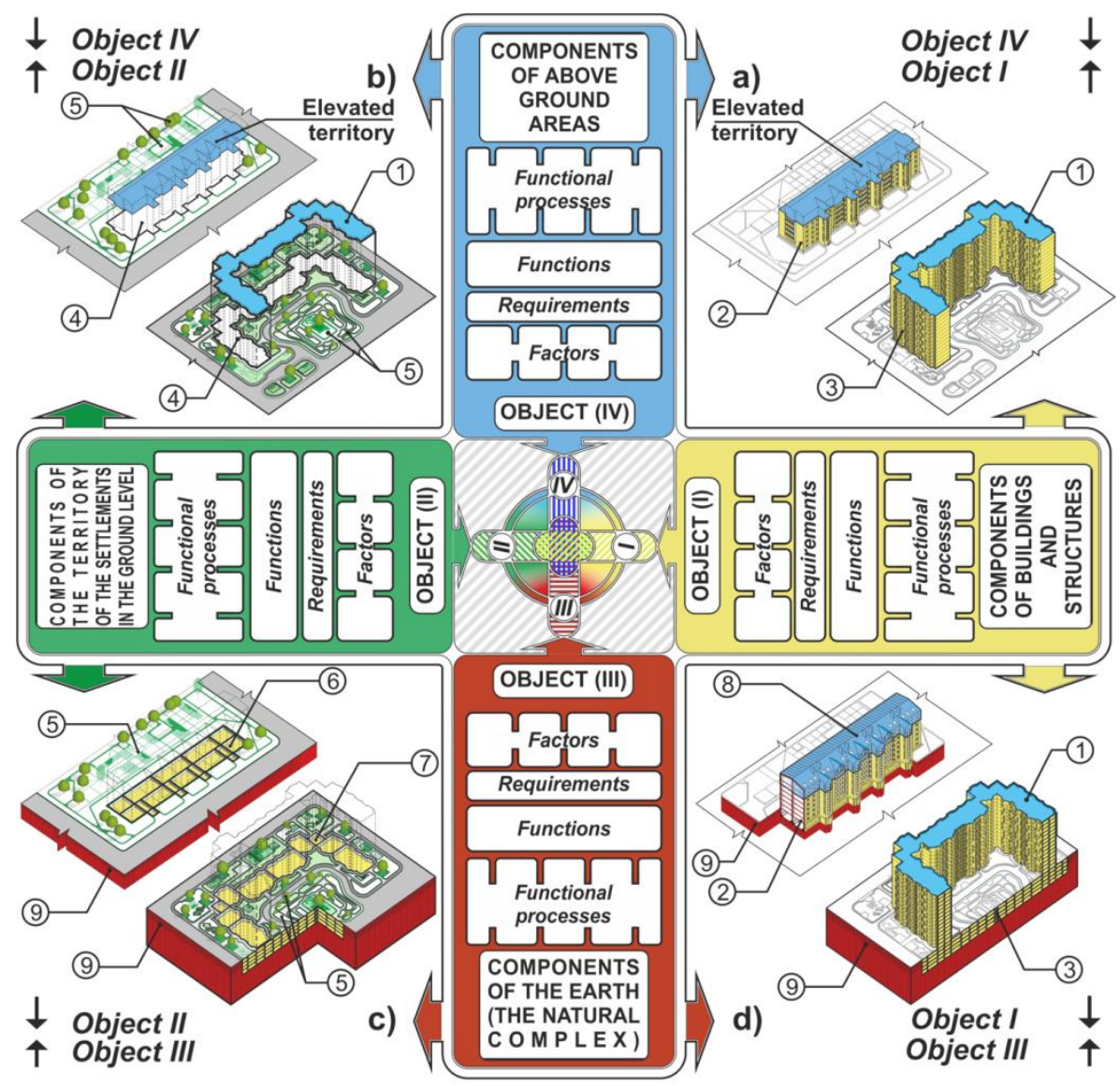

a, b, c, d - interconnections according to the components of the objects : I-IV, IV-II, II-III, I-III

Elevated territory - (covering or attic flooring of the residential buildings);

1 - operated flat roof;

2 - existing 5-storey residential building (renovated without demolition);

3 - new apartment building (renovated with demolition);

4 - building area of the residential house on the land duplicated by the elevated area;

5 - landscaping and greening of the land;

6 - build-up area of the existing residential building;

7 - build-up area of the new multi-storey residential building;

8 - superstructure, attic on the elevated (above ground area) territory;

9 - earth - hard shell (lithosphere)

Fig 1. The model of the structural organization of the components of the urban planning formations: the ground, underground, underwater, above-ground buildings and structures (object I); - the territories of the settlements and regions in the level of the land surface and aquatic environment (object II); - the natural land complex (object III); - the above ground areas (object IV).

The components of these objects in the model of their structural organization in urban planning entities, providing an integrated approach to the effective territorial-spatial development of the settlements, are an objective reality that guarantees the livelihoods of the settlements and regions.

At the same time, successful organization of urban planning activities, in which its participants use only the model of structural organization of the whole variety of the components of urban planning entities to predict their urban planning capabilities while taking into account the socio-economic, environmental, territorial features, specificity, is a necessary but not sufficient condition. There is no coordinating system for organizing the 
planning of the settlements and regions, urban planning and architectural and construction design, scientific research and vocational education, which allows government agencies to combine the interests of the participants in urban planning development.

\section{Methods}

The development of the coordinating system (Figure 2) includes interrelated positions of the urban planning activities carried out on the basis of the structural organization model of the components of the urban planning entities in the settlements. In the position of urban planning put:

1. the general structure of the scientific, planning and design studies of the territorialspatial development of the settlements;

2. the need for the research;

3. the principles of the formation of the scientific-methodical and normativetechnical documentation;

4. the principles, conditions, features of the organization of the vocational education.

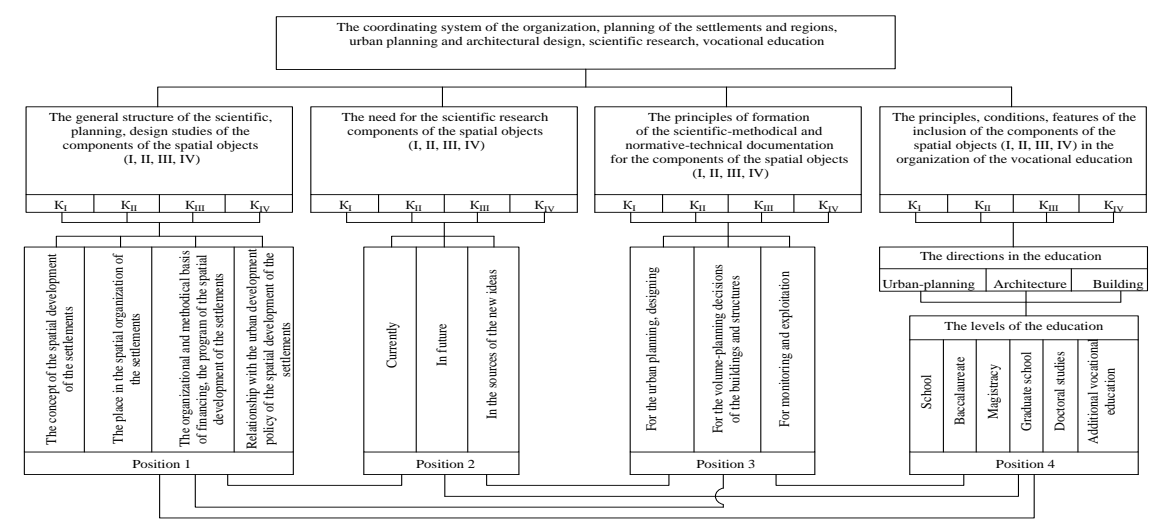

Fig.2 The interconnection and the interdependence of the positions of the coordinating system.

The content of the positions of the coordinating system is based on the use of regularities in the relationship of the components of the model of their structural organization in urban planning entities.

Organized in such a way, the consistency and complexity of urban planning activity serves to unite the interests and organization of coordinated actions of the participants of urban planning activities in making decisions that ensure a unified approach to the development of diverse concepts of planning the settlements and regions.

In turn, the results of organized systematic and integrated urban planning activities are associated with providing for its participants:

1. the real contribution of science to the development and implementation of urban planning policies implemented by the administrations, government agencies, etc.;

2. a compromise between them;

3. reasonable inclusion of the urban planning components in the planning structure of the settlements;

4. the conditions for improvement in the preparation of the bachelors, masters, graduate students, doctoral students in the areas of urban planning, architecture, construction, etc.

Equal "weight" of the components of the structural model of the organization in the 
urban planning entities and in the positions of the coordinating system is used to take into account both long-term planning of the territorial-spatial development of the settlements, and short-term, aimed at the development of urban planning policy in a specific territory. At the same time, consideration is given to the general socio-economic and environmental phenomena, trends and processes.

\section{Results}

The use of the coordinating system that ensures the targeted and integrated integration of the components of the structural model of the organization into the urban planning formations of the settlements is oriented: firstly, first of all on general problems, covering theoretical assumptions and practical implementation; secondly, to develop the regional and municipal planning, general plans and the settlement planning projects, schemes for planning the organization of the land plots for the new construction or renovation of the existing settlement development.

At the same time, the features, conditions and specifics of the territorial planning, zoning of the territory, the types of development, the territorial-construction resources (TSR - territories free of development in the settlement, elevated territories, underground buildings and structures that are inconvenient for agricultural production), land use and land management, etc.

This approach determines the systemic interconnection of the positions of the coordinating system, focused both on the government departments, regional and local administrative bodies responsible for the developing urban planning policies for the development of regions and settlements, as well as on scientific, design and educational institutions and individual professionals.

The model of the structural organization of the components in the urban planning entities in conjunction with the positions of the coordinating system allows to differentiate the functional, technological, physical-technical, technical loads that are important for the spatial organization of the settlements, the formation of the organizational and methodological structure of their development and financing in the development of programs, concepts planning in conjunction with the urban policy.

Such differentiation provides the establishment in programs, concepts of development of the settlements of their needs in the components of the urban planning entities, the conditions and opportunities for the emergence of the sources of new scientific ideas for the structural and functional transformations of the settlements depending on the regional characteristics.

\section{Discussion}

Determining the need for the components of the urban planning entities according to their structural organization model and the position of the coordinating system plays an important role in assessing and controlling the results of their inclusion in:

1. Planning of the settlements and regions;

2. The urban planning and architectural design of the settlements;

3. Development of the scientific, organizational, educational, methodological and regulatory and technical documents;

4. Implementation of the scientific research, monitoring;

5. Professional education.

The consistency and complexity of the results of the identified needs for the components of urban planning entities ensure the development of an interrelated structure 
for collecting and processing information necessary for organizing monitoring.

Such information allows taking into account the general socio-economic conditions in the structural organization model of the components of urban planning entities and the positions of the coordinating system, which regulate the needs and possibilities of using the territorial-spatial resources, the natural complex of the earth, new technologies, energy costs, recreation and tourism areas, and others. These ones and other aspects stimulate such actions of the executors of the coordinating system, such as:

1. Analysis of the future scenarios of the territorial-spatial development of the regions and settlements;

2. Assessment of the impact of large-scale economic changes on the interrelated processes of planning local socio-economic development and planning of the settlements and the region;

3. Defining the role of the building policy in the settlements;

4. Integrated planning of the socio-economic development of the settlements and their territorial-spatial organization.

Against the background of general socio-economic and urban planning aspects in the actions of the executors of the coordinating system, in accordance with the content and interrelation of its positions, the main direction is maintained and the prospect of using the components of the structural model of their organization in urban planning entities is substantiated.

At the same time, the prospect of using the components of the model of their structural organization in urban planning entities is substantiated by analyzing and synthesizing the resulting system of interdependent results of the scientific, planning, design and educational activities, coordinated by management bodies (Figure 3 ).

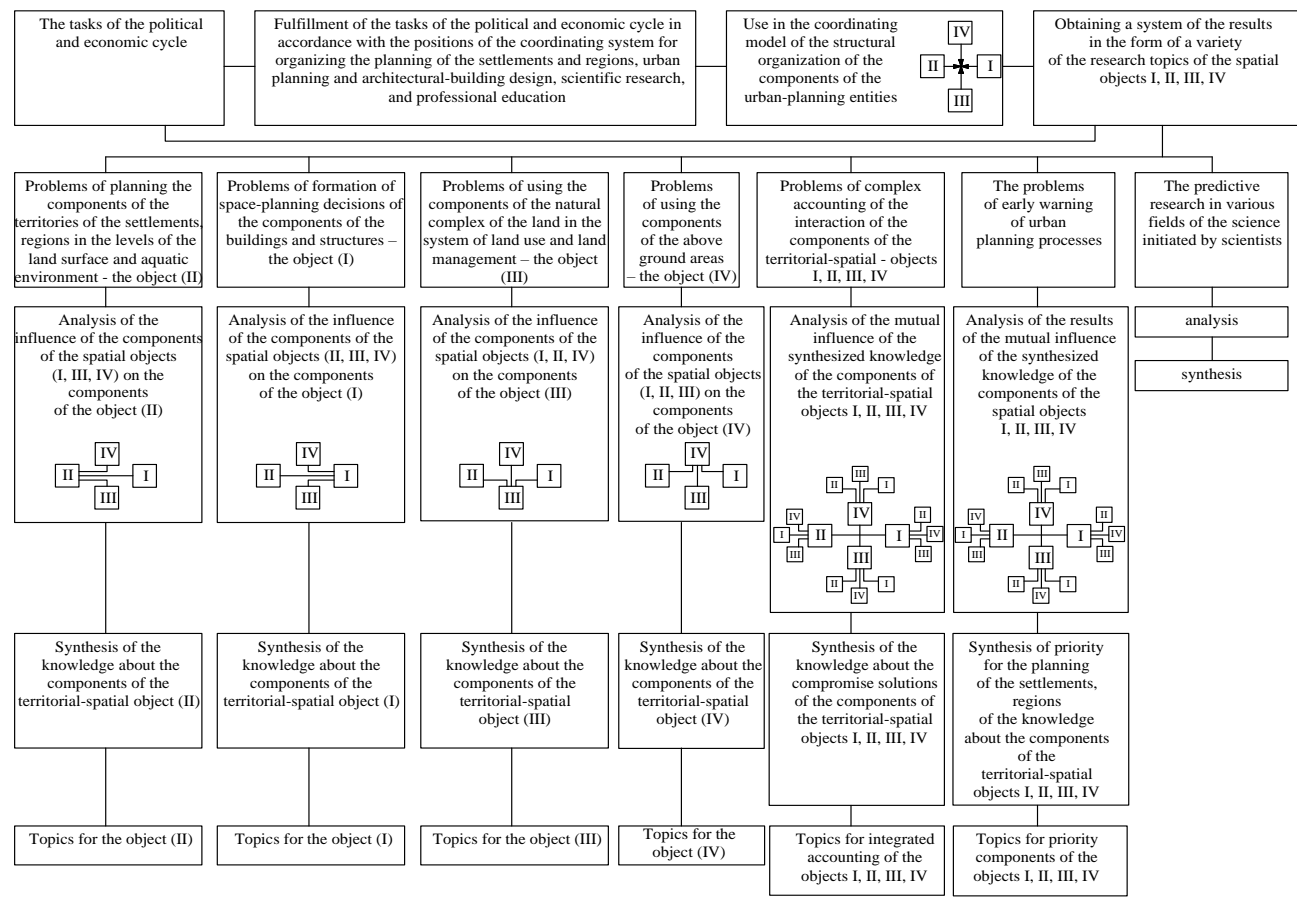

Fig.3 Systemic assessment of the results of the urban planning activities during the political and economic cycle. 
The objectivity of the results, which determine the future use of the components of urban planning entities, should consist in reflecting the real processes of social development, which will allow management bodies to improve the urban planning policy in accordance with the interrelated positions of the coordinating system.

The viability and the prospect of using the system of results when planning the settlements and regions depends on the usefulness of the conditions created by the participants of the urban planning activities in relation to each of the components of urban planning entities.

Modern conditions of planning of the settlements and regions are associated with the complexity and speed of socio-economic changes, limited natural resources, location and amount of financial resources in regions and the settlements, the impact of technological innovations and increased public awareness. Therefore, systemic, full-fledged and effective inclusion of the components of the above-ground, underground, above-ground and underwater buildings and structures the territories of the settlements in the level of the land surface and aquatic environment; natural land complex; the aboveground territories included in the model of their structural organization should become an integral part of management decision making.

The role of such decisions, due to the interconnection and interdependence of the model of the structural organization of the components of urban planning entities and the positions of the coordinating system, is to ensure that:

- firstly, different points of view (socio-economic, functional-technological, technical, and compositional-artistic nature); trends in the approach and development strategy of the regions and settlements; conditions for the development of the urban development policy of the territorial-spatial planning of the settlements; conditions for the organization of vocational education;

- secondly, the ways of purposeful and objective establishment of promising and toppriority scientific, planning and design themes, the implementation of which in time corresponds to the tasks of the political and economic cycle;

- thirdly, prognostic data from different fields of the science for an early warning system.

\section{Conclusions}

Solving a wide range of the government tasks in the urban development activities based on the developed methodology for coordinating professional activities of the scientists, planners and planners, government bodies, representatives of the urban, architectural and construction education institutions, investing organizations and residents of the settlements will provide objective conditions for mutual understanding between them and, as a result, reasonable compromise in the results of the work.

\section{References}

1. Y. V. Alekseev, Urban-planning bases for the development and reconstruction of residential buildings (2009)

2. Y. V. Alekseev, Architec. Constr. Rus. 3(227), 86 (2018)

3. V. Y. Alpatov, A. A. Sakharov, O. Y. Veremeenko, A. A. Lukin, MATEC Web of Conferences 86, 02021 (2016). DOI: 10.1051/matecconf/20168602021

4. O.M. Smirnova, 9(8), 1724-1732 (2018)

5. L. V. Pushkareva, O. A. Galochkina, O. L. Bezgacheva, Espacios 40(4), 22 (2019) 